\title{
Toxic epidermal necrolysis in an 8-year-old girl successfully treated with cyclosporin A, intravenous immunoglobulin and plasma exchange
}

\begin{abstract}
Marzena Zielińska ${ }^{1}$, Łukasz Matusiak², Waldemar Gołębiowski ${ }^{1}$, Katarzyna Swiątek ${ }^{3}$, Iwona Chlebicka², Joanna Maj², Jacek Szepietowski²
\end{abstract}

1Paediatric Intensive Care and Anaesthesiology, Wroclaw Medical University, Wroclaw, Poland 2Department of Dermatology, Venereology and Allergology, Wroclaw Medical University, Wroclaw, Poland ${ }^{3}$ Department of Pediatric Surgery and Urology, Wroclaw Medical University, Wroclaw, Poland

Adv Dermatol Allergol 2018; XXXV (2): 217-221

DOI: https://doi.org/10.5114/ada.2018.75247

Stevens-Johnson syndrome (SJS) and toxic epidermal necrolysis (TEN) are two rare, acute and severe dermatoses. They are characterized by different extent of epidermal necrolysis. Toxic epidermal necrolysis is associated with high mortality and it is one of the most severe disorders in dermatology. The most frequent and predominant triggers of TEN are drugs. The annual risk of TEN in the general population is calculated as 0.4-1.2 per million $[1,2]$. The prevalence of this toxic reaction is unknown in children. It looks likely to be less frequent than in the adult population $[1,2]$. The treatment of TEN is difficult and there is no optimal management established. Several therapy modalities have been proposed and analyzed [2]. We present a case of very severe TEN in an 8-year-old child successfully treated with combination therapy of cyclosporin A, intravenous immunoglobulin and plasma

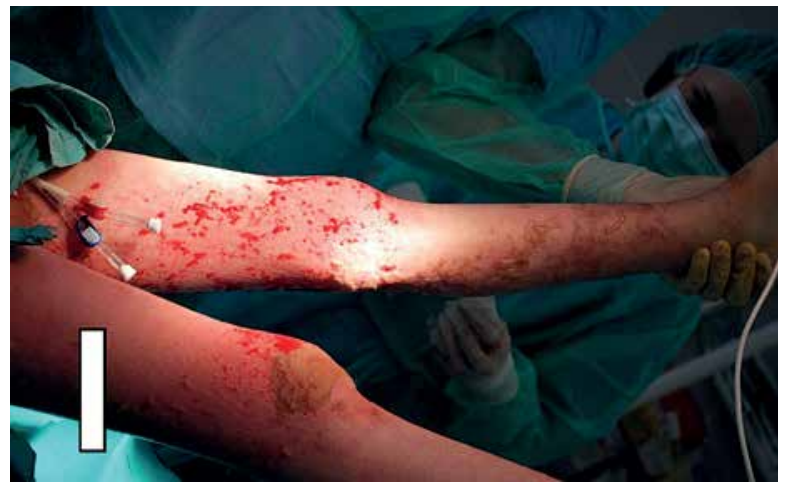

Figure 1. Skin lesion on the legs exchange. We would like also to draw attention to the difficulties in diagnosing TEN in such young patients.

An 8-year-old girl in a very serious condition was admitted to the Pediatric Intensive Care Unit (PICU).

Before admission she had been hospitalized in the Department of Infectious Diseases. On the basis of clinical manifestations (high fever, cough, photophobia, blistering skin eruptions on erythematous background) and laboratory tests (C-reactive protein $209 \mathrm{mg} / \mathrm{dl}$, norm: $>5 \mathrm{mg} / \mathrm{dl}$; procalcitonin 11.03, norm: 0.05, aspartate aminotransferase $106 \mathrm{IU} / \mathrm{l}$, norm: 0-45 IU/l, alanine aminotransferase 141 IU/l, norm: 0-40) staphylococcal scalded skin syndrome was diagnosed and therapy with amoxicillin $90 \mathrm{mg} / \mathrm{kg} /$ day was initiated.

On admission to the PICU the girl was conscious with efficiency of circulatory and respiratory systems. Erythematous and blistering eruptions on the face, trunk

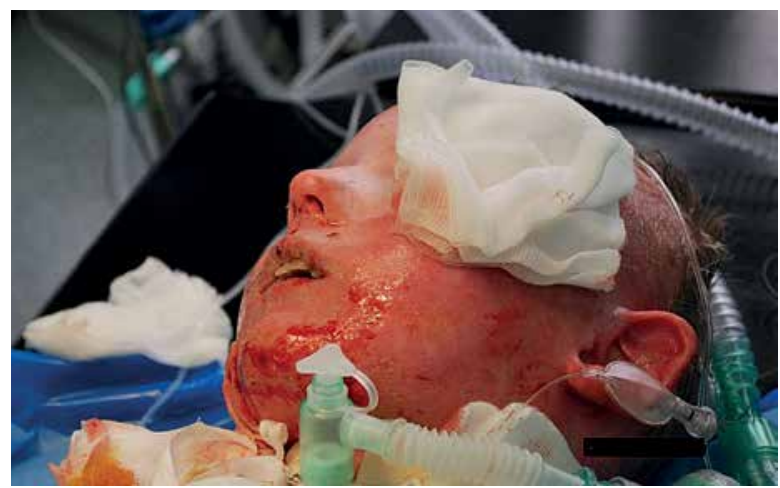

Figure 2. Skin lesions on the face

Address for correspondence: Iwona Chlebicka MD, Department of Dermatology, Venereology and Allergology, Wroclaw Medical University, 1 Chałubińskiego St, 50-638 Wroclaw, Poland, phone: +48 509689 147, +48 509689 147, fax: +48 509689 147,

e-mail: iwonak4wsk@interia.pl

Received: 21.01.2017, accepted: 25.03.2017. 
Table 1. Review of literature

\begin{tabular}{|c|c|c|c|c|c|}
\hline Authors (year) & $\begin{array}{l}\text { Number of } \\
\text { patients in } \\
\text { study }\end{array}$ & $\begin{array}{c}\text { Pediatric } \\
\text { patients with } \\
\text { TEN }\end{array}$ & $\begin{array}{l}\text { Involvement } \\
\text { (\% TBSA) }\end{array}$ & $\begin{array}{l}\text { Mortality } \\
\text { (\%) }\end{array}$ & Treatment for the pediatric case \\
\hline Adzick et al. (1985) & 4 & 4 & $86 \pm 6$ & 25 & Adjuvant therapy \\
\hline Ruiz-Maldonado (1985) & 5 & 5 & $>70$ & $\mathrm{~N} / \mathrm{A}$ & Adjuvant therapy \\
\hline Heimbach et al. (1987) & 19 & 3 & $75 \pm 5$ & 16 & Adjuvant therapy \\
\hline Revuz et al. (1987) & 87 & N/A & $39 \pm 3$ & 25 & Adjuvant therapy \\
\hline Jones et al. (1989) & 9 & 9 & $60 \pm 6.5$ & 11 & Adjuvant therapy \\
\hline Taylor et al. (1989) & 6 & 6 & 72.5 & 17 & $\begin{array}{l}\text { Adjuvant therapy and topical xenograft } \\
\text { (pig skin) }\end{array}$ \\
\hline Prendiville et al. (1989) & 7 & 7 & $\mathrm{~N} / \mathrm{A}$ & 0 & Adjuvant therapy \\
\hline Murphy et al. (1997) & 44 & N/A & $52 \pm 5$ & 36 & Adjuvant therapy \\
\hline Szepietowski et al. (1997) & 3 & 1 & 73 & 0 & Cyclosporin A and corticosteroids \\
\hline McGee et al. (1998) & 36 & $N / A$ & $63 \pm 5$ & 31 & Adjuvant therapy \\
\hline Sheridan et al. (1999) & 10 & 10 & $76 \pm 6$ & 0 & Adjuvant therapy \\
\hline Magina et al. (2000) & 1 & 1 & 95 & 0 & IVIG and adjuvant therapy \\
\hline Spies et al. (2001) & 15 & 15 & $76 \pm 5$ & 7 & $\begin{array}{l}\text { Adjuvant therapy and human allograft skin } \\
\text { or xenograft }\end{array}$ \\
\hline Inamo et al. (2002) & 2 & 2 & N/A & 0 & Adjuvant therapy and intravenous ulinastatin \\
\hline John et al. (2002) & 2 & 2 & 80 & 0 & $\begin{array}{l}\text { Adjuvant therapy and amniotic membrane } \\
\text { transplantation }\end{array}$ \\
\hline Lee et al. (2002) & 1 & 1 & N/A & 0 & Adjuvant therapy \\
\hline Sheridan et al. (2002) & 11 & 11 & $76 \pm 6$ & 0 & Adjuvant therapy \\
\hline Uzum et al. (2002) & 1 & 1 & N/A & 100 & Adjuvant therapy \\
\hline Metry et al. (2003) & 8 & 8 & N/A & 0 & IVIG and adjuvant therapy \\
\hline Tristani-Firouzi et al. (2002) & 8 & 8 & 67 & 0 & IVIG and adjuvant therapy \\
\hline Mayorga et al. (2003) & 1 & 1 & $\mathrm{~N} / \mathrm{A}$ & 0 & IVIG and adjuvant therapy \\
\hline Beerhosrt et al. (2003) & 1 & 1 & N/A & 100 & Adjuvant therapy \\
\hline Al-Mutairi et al. (2004) & 12 & 4 & 57.5 & 100 & IVIG and adjuvant therapy \\
\hline Bygum et al. (2004) & 1 & 1 & $50-60$ & 0 & $\begin{array}{l}\text { IVIG, intravenous steroids and adjuvant } \\
\text { therapy }\end{array}$ \\
\hline Kalyoncu et al. (2004) & 1 & 1 & 90 & 0 & $\begin{array}{l}\text { IVIG, granulocyte colony-stimulating factor and } \\
\text { adjuvant therapy }\end{array}$ \\
\hline Yildizdas et al. (2005) & 1 & 1 & 30 & 0 & Adjuvant therapy \\
\hline Lam et al. (2005) & 1 & 1 & N/A & N/A & N/A \\
\hline Ziora et al. (2005) & 1 & 1 & 90 & 0 & $\begin{array}{l}\text { IVIG, intravenous corticosteroids and adjuvant } \\
\text { therapy }\end{array}$ \\
\hline Mangla et al. (2005) & 10 & 10 & 66.7 & 0 & IVIG and adjuvant therapy \\
\hline Kobayashi et al. (2006) & 1 & 1 & 40 & 0 & $\begin{array}{l}\text { IVIG, intravenous steroids, adjuvant therapy } \\
\text { and amniotic membrane transplantation }\end{array}$ \\
\hline Elkharaz et al. (2006) & 7 & 5 & $\mathrm{~N} / \mathrm{A}$ & 0 & $\begin{array}{l}\text { IVIG, intravenous steroids and adjuvant } \\
\text { therapy }\end{array}$ \\
\hline Aihara et al. (2006) & 1 & 1 & $>30$ & 0 & $\begin{array}{l}\text { Cyclosporin } \mathrm{A} \text {, intravenous corticosteroids and } \\
\text { adjuvant therapy }\end{array}$ \\
\hline Chiossi et al. (2007) & 1 & 1 & $\mathrm{~N} / \mathrm{A}$ & 0 & $\begin{array}{l}\text { IVIG, intravenous steroids and adjuvant } \\
\text { therapy }\end{array}$ \\
\hline Clayton et al. (2007) & 1 & 1 & 80 & 0 & Adjuvant therapy \\
\hline
\end{tabular}


Table 1. Cont.

\begin{tabular}{|c|c|c|c|c|c|}
\hline Authors (year) & $\begin{array}{l}\text { Number of } \\
\text { patients in } \\
\text { study }\end{array}$ & $\begin{array}{l}\text { Pediatric } \\
\text { patients with } \\
\text { TEN }\end{array}$ & $\begin{array}{l}\text { Involvement } \\
\text { (\% TBSA) }\end{array}$ & $\begin{array}{l}\text { Mortality } \\
(\%)\end{array}$ & Treatment for the pediatric case \\
\hline Gerdts et al. (2007) & 19 & 3 & N/A & 21 & Adjuvant therapy \\
\hline Serati (2007) & 1 & 1 & 90 & 0 & IVIG and adjuvant therapy \\
\hline Fine et al. (2008) & 1 & 1 & $\mathrm{~N} / \mathrm{A}$ & 0 & Systemic steroids and adjuvant therapy \\
\hline Sevketoglu et al. (2009) & 1 & 1 & 60 & 0 & IVIG and adjuvant therapy \\
\hline Mamishi et al. (2009) & 7 & 3 & $\mathrm{~N} / \mathrm{A}$ & 0 & IVIG and adjuvant therapy \\
\hline Dillon et al. (2010) & 6 & 3 & $>50$ & 0 & $\begin{array}{l}\text { IVIG, Versajet system with allograft } \\
\text { and adjuvant therapy }\end{array}$ \\
\hline Koh et al. (2010) & 1 & 1 & $\mathrm{~N} / \mathrm{A}$ & 100 & IVIG and adjuvant therapy \\
\hline Yang et al. (2010) & 36 & 6 & N/A & 0 & $\begin{array}{l}\text { IVIG, intravenous corticosteroids and adjuvant } \\
\text { therapy }\end{array}$ \\
\hline $\begin{array}{l}\text { Ferrándiz-Pulido et al. } \\
\text { (2011) }\end{array}$ & 14 & 6 & 88 & 16 & $\begin{array}{l}\text { IVIG or/and intravenous steroids and adjuvant } \\
\text { therapy }\end{array}$ \\
\hline Bouziri et al. (2011) & 1 & 1 & 40 & 0 & Adjuvant therapy \\
\hline Finkelstein et al. (2011) & 55 & 5 & N/A & 20 & IVIG, corticosteroids and adjuvant therapy \\
\hline Norris et al. (2012) & 1 & 1 & 60 & 0 & Adjuvant therapy \\
\hline Aihara et al. (2012) & 1 & 1 & 70 & 0 & $\begin{array}{l}\text { Plasma exchange, intravenous steroids, IVIG } \\
\text { and adjuvant therapy }\end{array}$ \\
\hline Barvaliya et al. (2012) & 1 & 1 & 66 & 100 & Intravenous steroids and adjuvant therapy \\
\hline Calka et al. (2013) & 1 & 1 & $>30$ & 0 & Intravenous steroids and adjuvant therapy \\
\hline Scott-Lang et al. (2014) & 1 & 1 & $\mathrm{~N} / \mathrm{A}$ & 0 & IVIG, infliximab and adjuvant therapy \\
\hline Kreft et al. (2014) & 1 & 1 & N/A & 0 & IVIG, infliximab and adjuvant therapy \\
\hline Sethuraman et al. (2012) & 20 & 8 & N/A & 37 & $\begin{array}{l}\text { Intravenous steroids in } 7 \text { patients, } 1 \text { patient } \\
\text { received cyclosporin A, adjuvant therapy }\end{array}$ \\
\hline El-Naggari et al. (2013) & 1 & 1 & 60 & 0 & IVIG and adjuvant therapy \\
\hline Calvano et al. (2013) & 1 & 1 & & 0 & $\begin{array}{l}\text { IVIG, plasma exchange, intravenous steroids } \\
\text { and adjuvant therapy }\end{array}$ \\
\hline Gogia et al. (2013) & 1 & 1 & N/A & 100 & Adjuvant therapy \\
\hline $\begin{array}{l}\text { Atanasković-Marković } \\
(2013)\end{array}$ & 1 & 1 & $>70$ & 0 & $\begin{array}{l}\text { Intravenous corticosteroids, IVIG and adjuvant } \\
\text { therapy }\end{array}$ \\
\hline Yi et al. (2014) & 1 & 1 & 90 & 0 & IVIG and adjuvant therapy \\
\hline Klosová et al. (2014) & 1 & 1 & 90 & 0 & Adjuvant therapy and biological xenograft \\
\hline Kumar Das et al. (2014) & 29 & 6 & $60-90$ & 66 & Systemic steroids and adjuvant therapy \\
\hline Romero-Tapia et al. (2015) & 2 & 1 & N/A & 0 & IVIG and adjuvant therapy \\
\hline Sniderman et al. (2015) & 1 & 1 & N/A & 0 & Systemic corticosteroids and adjuvant therapy \\
\hline Quirke et al. (2015) & 41 & & N/A & 0 & Adjuvant therapy \\
\hline Rizzo et al. (2015) & 21 & 14 & & 9.5 & IVIG and adjuvant therapy \\
\hline Hinc-Kasprzyk et al. (2015) & 1 & 1 & $\mathrm{~N} / \mathrm{A}$ & 0 & Plasma exchange \\
\hline Yamane et al. (2016) & 35 & 3 & $\mathrm{~N} / \mathrm{A}$ & 0 & $\begin{array}{l}\text { Systemic steroids or/and other treatment and } \\
\text { adjuvant therapy }\end{array}$ \\
\hline Çekiç et al. (2016) & 11 & 4 & $\mathrm{~N} / \mathrm{A}$ & 0 & $\begin{array}{l}3 \text { patients: IVIG, systemic steroids, } \\
\text { antihistaminic drugs, } 1 \text { patient: IVIG, systemic } \\
\text { steroids, antihistaminic drugs and cyclosporin }\end{array}$ \\
\hline Techasatian et al. (2016) & 30 & 6 & $\mathrm{~N} / \mathrm{A}$ & 33 & $\begin{array}{l}5 \text { patients: systemic steroids and adjuvant } \\
\text { therapy } \\
1 \text { patient: IVIG and adjuvant therapy }\end{array}$ \\
\hline
\end{tabular}


and extremities (encompassing about $90 \%$ of total body surface area) were observed (Figure 1). Nikolsky's sign was highly positive. Bloody erosions on all mucous membranes (in the oral cavity, genital region and eyes) were also visible (Figure 2).

During the first day of hospitalization in the PICU the girl was still treated as having staphylococcal infection. The cultures of the skin, throat and blood were taken. Antibiotic therapy was continued. However her clinical condition worsened. Cultures were negative. The biopsy from the skin lesion was taken. Because of the respiratory and circulatory insufficiency, the girl was intubated and pharmacological treatment with pressor amines was introduced.

Astute medical anamnesis from parents revealed that 4 weeks before this acute disorder, ambulatory therapy with carbamazepine because of generalized epileptic seizures without loss of consciousness was initiated. On the basis on clinical manifestations, anamnesis and histological examination, toxic epidermal necrolysis was diagnosed. Immunoglobulin intravenous in a dose of $2 \mathrm{~g} / \mathrm{kg}$ in total (for 5 days) and cyclosporin A (CsA) in a dose of $3 \mathrm{mg} / \mathrm{kg} /$ day intravenously (for 20 days) were administered. Because of the severe condition of the girl, six plasma exchange cycles (Prismaflex/Gabro ${ }^{\circledast}$ ) were performed.

After 40 days of endotracheal intubation and mucous membranes epithelization the girl was extubated. During these forty days the child's life was constantly threatened. She required aggressive intravenous hydration, parenteral nutrition, broad-spectrum antibiotics (because of a few sepsis events confirmed by various blood cultures), transfusions of blood and albumins, supportive topical therapy (with gauze wound dressing), active ophthalmological service, rehabilitation and surgical help.

This combination therapy was successful. Persisting complications of severe TEN and its treatment in this patient are a secondary nutritional disturbance, loss of muscle mass, reduced mobility and anxiety-depressive syndrome. The girl is also still under ophthalmological control because of corneal abrasion.

The diagnosis of toxic epidermal necrolysis is made on the basis of the clinical condition, anamnesis and histological examination of a skin biopsy [3, 4]. The presented case shows that clinical symptoms of TEN can resemble staphylococcal scalded skin syndrome. However, staphylococcal scalded skin syndrome is very uncommon in populations over 5 years old $[3,4]$. What was also typical of toxic epidermal necrolysis was a correlation with initiation of carbamazepine therapy 4 weeks before the skin reaction. Pooled analysis of risk factors for SIS and TEN in children confirmed that carbamazepine is one of four highest-risk factors. The other suspected drugs are: lamotrigine, phenobarbital and anti-infective sulfonamides [5-7]. We confirmed clinical diagnosis with histological examination. There is some research on possible indicators which can help in early diagnosis of TEN. The first results show that an elevated level of serum granulysin may be a helpful biomarker for the early phase of SIS/TEN [8].

A child with skin necrosis involving more than $30 \%$ of its surface must be treated in the PICU due to the massive loss of fluids through the body shell, electrolyte imbalance, and the seizure of the mucous membranes of the mouth and respiratory tract. In cases similar to ours, it is necessary to perform a tracheotomy because of mucous changes in the respiratory tract. Deprivation of the immunological barrier (epidermis) exposes to an elevated risk of severe infections, associated also with the use of immunosuppressive therapy of TEN. The treatment of drug-induced toxic epidermal necrolysis is always a huge challenge. There are no guidelines established. The systemic review of treatment of SJS/TEN in children showed that the four most frequent treatment options were: intravenous immunoglobulin (IVIG), systemic steroids, dressings with or without the surgical approach, and support treatment [2] (Table 1). The usage of steroids is still controversial but they are often used by clinicians in the treatment of children with TEN (Table 1). Therapy with cyclosporin A (CsA) is usually effective in adults [9] but has numerous side effects $[9,10]$. In the literature we found only limited reports of children with TEN successfully treated with cyclosporin A [10] and cyclosporin in conjunction with corticosteroids [11]. Use of off-label intravenous immunoglobulin seems to be not as risky as immunosuppressive agents [12-14]. In the literature we found numerous reported cases of children with TEN who were successfully treated with IVIG [12-15] (Table 1). Plasma exchange in patients with toxic epidermal necrolysis is still an infrequent method of therapy because of the costs. However, the results are very promising, especially in pediatric patients with TEN [16-18].

We are presenting our TEN patient because to the best of our knowledge it is the first case in the child population when such combination of treatment modalities was used.

\section{Conflict of interest}

The authors declare no conflict of interest.

\section{References}

1. Mittmann N, Chan BC, Knowles S. IVIG for the treatment of toxic epidermal necrolysis. Skin Therapy Letter 2007; 121: 7-9.

2. Del Pozzo-Magana BR, Lazo-Langner A, Carleton B, et al. A systemic review of treatment of drug-induced StevensJohnson syndrome and toxic epidermal necrolysis in children. J Popul Ther Clin Pharmacol 2011; 18: 121-33.

3. Chave TA, Mortimer NJ, Sladden M.J. Toxic epidermal necrolysis: current evidence, practical management and future directions. Br J Dermatol 2005; 153: 241-53. 
4. Ghislain PD, Roujeau JC. Treatment of severe drug reactions: Stevens-Johnson syndrome, toxic epidermal necrolysis and hypersensitivity syndrome. Dermatol Online J 2002; 8: 5.

5. Levi N, Bastuji-Garin S, Mockenhaupt M, et al. Medications as risk factors of Stevens-Johnson syndrome and toxic epidermal necrolysis in children; a pooled analysis. Pediatrics 2009; 123: 297-304.

6. Bohan KB, Mansuri T. Anticonvulsant hypersensitivity syndrome: implications for pharmaceutical care. Pharmacotherapy 2007; 27: 1425-39.

7. Brooks M. Risk allele flags carbamazepine hypersensitivity in Europeans. N Engl J Med 2011; 364: 1134-43.

8. Lipper G. A new test for the reduction of Stevens-Johnson syndrome. J Am Acad Dermatol 2011; 65: 65-8.

9. Silny W, Dańczak-Pazdrowska A, Smuszkiewicz P, et al. Therapeutic success in a case of toxic epidermal necrolysis with dramatic course. Postep Derm Alergol 2010; 27: 308-13.

10. Aihara $Y$, Ito R, Ito $S$, et al. Toxic epidermal necrolysis in a child successfully treated with cyclosporine $A$ and methyloprednisolone. Pediatr Intern 2007; 49: 659-62.

11. Szepietowski J, Wasik F, Szybejko-Machaj G, Maj J. Toxic epidermal necrolysis successfully treated with cyclosporine. Report of three cases. J Eur Acad Derm Venereol 1997; 9: 169-72.

12. Metry D, Jung P, Levy ML. Use of intravenous immunoglobulin in children with Stevens-Johnson syndrome and toxic epidermal necrolysis: seven cases and review of literature. Pediatrics 2003; 112: 1430-6.

13. Arca E, Köse O, Erbil H, et al. A 2-year-old girl with StevensJohnson syndrome/toxic epidermal necrolysis treated with intravenous immunoglobulin. Pediatr Dermatol 2005; 22: 317-20.

14. Yang Y, Xu J, Li F, et al. Combination therapy of intravenous immunoglobulin and corticosteroid in the treatment of toxic epidermal necrolysis and Stevens-Johnson syndrome: a retrospective comparative study in China. Int I Dermatol 2009; 48: $1122-8$.

15. Romero-Tapia SJ, Cámara-Combaluzier HH, Baeza-Bacab MA, et al. Use of intravenous immunoglobulin for Stevens-Johnson syndrome and toxic epidermal necrolysis in children: report of two cases secondary to anticonvulsants. Allergol Immunopathol 2015; 43: 227-9.

16. Bamichas G, Natse T, Christidou F, et al. Plasma exchange in patients with toxic epidermal necrolysis. Ther Apher 2002; 6: 225-8.

17. Hinc-Kasprzyk J, Polak-Krzemińska A, Głowacka M, OżógZabolska I. The use of plasmapheresis in a 4-year-old boy with toxic epidermal necrosis. Anaesthesiol Intensive Ther 2015; 47: 210-3.

18. Aihara Y, Oyama Y, Ichikawa K, et al. Toxic epidermal necrolysis in a 4-year-old boy successfully treated with plasma exchange in combination with methylprednisolone and i.v. immunoglobulin. J Dermatol 2012; 39: 951-2. 